\title{
Brief Communication: Evidence of Pathology on the Frontal Bone From Gongwangling
}

\author{
RACHEL CASPARI \\ Department of Anthropology, University of Michigan, \\ Ann Arbor, Michigan 48109-1382 \\ KEY WORDS paleopathology; early Homo; China
}

\begin{abstract}
The hominid fossil from Gongwangling (Lantian) is well known and described (Woo, [1965] Scientia Sinca 14:1032-1036; Woo [1966] Curr. Anthropol. 7:83-86; Wu and Dong [1985] in R Wu and J W Olsen (eds.): Palaeoanthropology and Pal eolithic Archaeology in the People's Republic of China [New York: Academic Press, pp. 79-89]; Wu and Poirier [1995] Human Evolution in China: A Metric Description of the Fossils and a Review of the Sites [Oxford: Oxford University Press]). However, evidence of pathology on the frontal bone has been previously unreported. Two lesions occur on the right supraorbital region that can be distinguished from marks of erosion prevalent on this specimen. These are discrete and irregularly shaped, with evidence of secondary bone formation surrounding them. The cause of the condition is uncl ear. Possibilities include trauma or abscess from an unspecified infection. AmJ PhysAnthropol 102:565-568, 1997. @ 1997 Wiley-Liss, Inc.
\end{abstract}

Some of the oldest Homo specimens from China were discovered in 1964 at a hill called Gongwangling, $17 \mathrm{~km}$ east of Lantian $\left(109^{\circ} 29^{\prime} \mathrm{E}, 34^{\circ} 11^{\prime} \mathrm{N}\right)$, Shaanxi province, in northwestern China (Wu and Poirier, 1995). These remains have been biostratigraphically correlated to early Pleistocene deposits and may be as old as 1.15 million years (An and $\mathrm{Ho}, 1989$ ). The Gongwangling material consists of six crani ofacial fragments repre senting a single individual. These include a large piece of crushed and distorted calvarium and five smaller pieces including two maxillary fragments with portions of the dentition. Although often discussed with and pictured with thecranium in reconstructions, the Lantian mandible is from a younger site, Chenjiawo, in the same region and is unrelated to the calvarium (Woo, 1966; Wu and Poirier, 1995).

The Gongwangling remains were found in silty clay deposits (Wu and Poirier, 1995), thoroughly embedded in concretion, and some of the hard matrix still covers parts of the specimen. The remains were subject to considerable erosion and distortion during fossilization and since their recovery have been preserved and strengthened with a thick application of shellac. These factors render some of the morphology difficult to interpret.

The largest piece of calvarium is almost entirely frontal bone which is virtually complete. This specimen preserves the supraorbital region on both sides, and its most outstanding characteristic is the great size of the supraorbital torus. In contrast to the size of the supraorbital torus, the dentition is small, and elements of the face, particularly the maxillae, are very gracile. Based on this gracility and the pattern of sexual dimorphism at Zhoukodian, the specimen is considered female (Woo, 1966; Wu and Poirier, 1995). It is clearly adult, as evidenced by extensive dental wear. On the basis of the degree of coronal suture closure, Wu estimated age at death between 30 and 40 years (Woo, 1966); however, as Weidenreich (1943)

Received 1 November 1995; accepted 2 F ebruary 1997. 


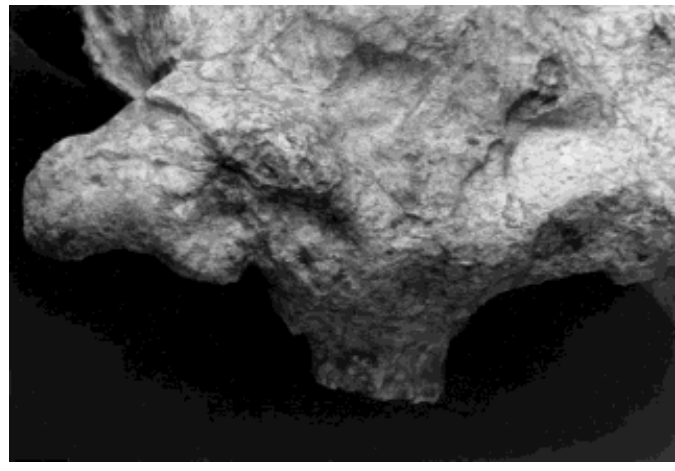

Fig. 1. The Gongwangling frontal, seetext for dimensions. Note the lesions on the right supraorbital torus and deformation of the bone surrounding them.

pointed out, ages based on suture closure standards derived for modern humans may not apply to earlier hominids.

The most completedescription of the fossil was published by Wu Rukang (Woo, 1965, 1966), and it is discussed briefly in other publications (e.g., Wu and Dong, 1985; Wu and Poirier, 1995) but these authors do not mention any evidence of pathology. However, from my study of the original, there are a pair of depressions on the right supraorbital torus that I interpret to be healed infractures or abscesses.

\section{DESCRIPTION}

The supraorbital portions of the Gongwangling frontal are massive and are clearly divided into anterior and superior components. The anterior surfaces are nearly vertical and are made to appear even more sheer as a consequence of erosion. The anterior and superior surfaces meet at roughly right angles, and their junction is marked by a pronounced ridge. The ridge is most prominent, and the supraorbital tori are thickest and highest in their medial and middle portions; laterally they are thinner and the distinction between the superior and anterior surfaces is diffuse, as the contour of the supraorbital torus becomes rounder. The lesions of interest occur on the sheer anterior surface of the right supraorbital torus, secondarily affecting the morphology of the ridge above the anterior surface. Most of the superior component of the torus is unaffected.

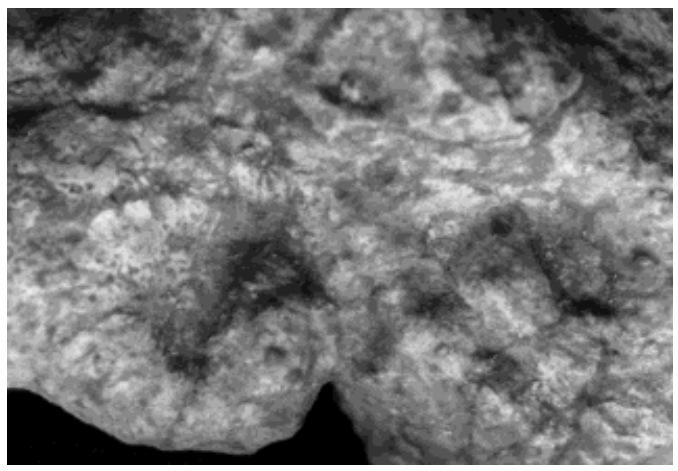

Fig. 2. Magnification of the lesions on the right supraorbital torus of the Gongwangling frontal. Note the unbroken bone surface on the lateral depression.

The entire damaged region, comprising both lesions, is irregularly shaped (Fig. 1). Its maximum dimensions are $25 \mathrm{~mm}$ wide and $15.6 \mathrm{~mm}$ high. Its most medial point is $12.5 \mathrm{~mm}$ from glabella, and its lateral border is $32 \mathrm{~mm}$ from the lateral edge of the torus, which appears to be broken just at the frontozygomatic suture. Vertically, the lesions incorporate much of the anterior surface of the torus. While the supraorbital torus extends $8.5 \mathrm{~mm}$ superior to the damaged area, inferiorly, $6 \mathrm{~mm}$ separates its most inferior part at its lateral aspect from the superior rim of the orbit. In comparison with the unaffected left side, the height of the right supraorbital torus is somewhat distorted (increased). The area above the depressions has a very rough and irregular surface that affects the contour of the ridge separating anterior and superior components. The bone inferior to the depressions is also distorted; a substantial portion (14.6 $\mathrm{mm}$ wide) of the superior orbital border, bounded by the supraorbital notch medially and another shallower notch laterally, projects inferiorly $3.7 \mathrm{~mm}$ below the normal surface of the orbital roof. This distortion above and bel ow the depressions may reflect secondary bone formation associated with the lesions (see bel ow).

The lesions themselves are two discrete punctuated depressions that are separated by a thin strip of apparently unaffected bone that has undergone postmortem erosion. The two lesions neverthel ess appear related and are probably the result of the same 
circumstances. They are separated by $6 \mathrm{~mm}$, and most of the strip separating them is narrower so that the two depressions are very close together. The more medial depression is shaped like an inverted $U$ and measures $10.5 \mathrm{~mm}$ in width and $8.5 \mathrm{~mm}$ in height. The rounded base of the $U$ points superiorly and somewhat laterally. The area between the arms of the $U$ is at the level of the original bone surface; it is higher than the eroded ridge separating the two depressions, is small, and looks like a discrete tubercle rising from the depressed area. The lateral depression is larger. It is oblong with its long axis lying vertically. Its greatest width is $9.6 \mathrm{~mm}$, while its height is $\mathbf{1 5 . 6}$ $\mathrm{mm}^{1}$

The lateral depression is $3.5 \mathrm{~mm}$ deep, while the medial U-shaped depression has a depth of $2.7 \mathrm{~mm}$. The edges of these depressi ons are smooth and slope gradual ly toward the centers of the lesions. The edges of the depressions are rounded; there are no sharp breaks, as one would expect from postmortem damage (Fig. 2). The lateral border of the large lateral depression is particularly gradual, and the continuity of the external table of bone remains unbroken. The vermiculate pattern is an attribute of the surface morphology of browridges (Tappen, 1980) and probably reflects the remodeling related to the development and the maintenance of these structures (Oyen and Russell, 1982). This pattern is apparent on some of the better preserved areas of the Gongwangling supraorbital region that appear to be unaffected by any pathological condition. It also appears on the floor of the lateral depression and can be traced uninterrupted to the surrounding normal bone surface. This suggests that the present bone surface was formed after the lesion developed. The bone surface is not preserved in the medial $\mathrm{U}$-shaped depression. Therefore, the relatively smooth edges of the lesions indicate that healing occurred, and in some areas, particularly the lateral border of the lateral

\footnotetext{
${ }^{1}$ The discrepancy between the width dimensions for the entire region and the individual components ( $25 \mathrm{vs} .26 .1 \mathrm{~mm}$ ) is the consequence of the variable width of the strip separating the two lesions-at the area of greatest width of the entire injury, the strip is narrower than its maximum width of $6 \mathrm{~mm}$. Additionally, the is narean herizontal plane. Consequently, the horizontal plane. Consequently, the greatest width of the injury as a whole is not equal to the sum of the widths of its parts.
}

indentation, one can trace the bone surface uninterrupted into the depths of the depression. These two factors appear to indicate that the alteration of the bone occurred antemortem and was not the result of erosion or other taphonomic agents.

Several aspects of the morphology surrounding the lesions may be associated with them. There is no doubt that some of the distortion of the Gongwangling frontal is due to cracks and breakage and the permeation of matrix into areas beneath the bone surface. However, inspection at low level magnification $(\times 30)$ suggests evidence of remodeling in the area immediately surrounding the depressions that may reflect responses to injury or infection. This is particularly observable above and bel ow the lesions, as discussed above, and to a lesser extent medially. Laterally there is no sign of secondary bone growth. Moreover, in some areas above the lesions the ridge has a very irregular "layered" surface. The distorted morphology around the legions may resemble bone with localized osteomylitis or periostitis (Ortner and Putschar, 1981; Webb, 1995), but the condition of the specimen precludes a full understanding of this feature. However, a comparison with the left supraorbital torus, which has al so sustained postmortem damage, suggests that neither postmortem hypermineralization nor infiltration with matrix into a broken or crushed area of bone is likely to account for the morphology of the bone immediately surrounding the lesions. This morphology probably is associated with the lesions themselves.

There is a long, matrix-filled crack intersecting the injured area, but this probably occurred postmortem and seems to be unrelated to the wound. It does, however, confuse the interpretation of the injury. The crack occurs where the lateral part of the supraorbital torus was separated from the rest of the frontal and then rejoined. The lateral piece is shifted slightly inferiorly, so that the supraorbital torus is further distorted by a ledge across its superior surface and a corresponding displacement on the superior border of the orbit. The crack occurs along the medial border of the lateral depression on theface of the torus. Since the crack incorpo- 
rates only the border of the depression, it does not invalidate the antemortem interpretation. In fact, since there does seem to be continuity across the crack that is disturbed by the displacement described above, it would appear that the lesion predates the events that caused the separation of the lateral portion of the torus. It is likely that the crack was caused by taphonomic variables unrelated to the source of the lesions.

\section{DISCUSSION}

The injury to the Gongwangling frontal differs from pathol ogical conditions found on other Chinese hominids. Comparison of the specimen with Zhoukoudian fossils and casts at the Institute of Vertebrate Paleontology and Pal eoanthropol ogy in Beijing show that the Lantian lesion differs from fractures in the crania from Zhoukoudian, many of which were described by Weidenreich $(1939,1943)$. The most common cranial injuries in the Zhoukoudian material are depressed fractures-relatively shallow, rounded indentations of variable size, often with fracture lines radiating out from them. The Gongwangling lesions are not depressed fractures. The lesions on the L 3 Zhoukoudian cranium are more acute than other depressed fractures from Zhoukoudian, but these are also unlike those on Gongwangling. The $\mathrm{H} 3$ frontal bone has the only injured brow ridge at Zhoukoudian, but this wound is also very different from the Gongwangling lesion. The H3 injury appears to be a long, relatively shallow depression, oriented horizontally al ong the top of the brow ridge. It widens laterally to cover most of the supraorbital torus. There is a deeper pit intercepting the depressed fracture, but this is not similar to the punctuated indentations seen on the Gongwangling frontal. Unlike depressed fractures reported from Zhoukoudian and el sewhere, there is no evidence of fracture lines radiating from the lesion on Gongwangling.

The cause of the damage to the Gongwangling frontal remains unclear. It may be the result of trauma, and/or the lesions themselves may be abscesses associated with infection. Their depth and irregular con- tours are compatible with such an interpretation. If so, the infection was probably highly localized. Since there are no similar indications on other parts of the skull, such as the frontal squama, the lesions seem unlikely to be manifestations of systemic disease. Whatever the cause, the lesions on the Gongwangling cranium appear to reflect a pathological condition and may deserve further study.

\section{ACKNOWLEDGMENTS}

I thank Zhang Yinyun and the Institute of VertebratePal eontology and Pal eoanthropology, Beijing, for permission to study specimens in their care and David Frayer, Maciej Henneberg, Jakov Radovčić, and Milford Wolpoff for helpful discussion and comments. I greatly appreciate the comments of Stephen Nawrocki and Kenneth Kennedy that substantially improved this note.

\section{LITERATURE CITED}

An Z, and Ho C (1989) New magnetostratigraphic dates of Lantian Homo erectus. Quaternary Research 33: 213-221.

Ortner DJ , and Putschar WGJ (1981) Identification of Pathological Conditions in Human Skeletal Remains. Smithsonian Contributions to Anthropology, Number 28. Washington, DC: Smithsonian Institution Press.

Oyen OJ, and Russell MD (1982) Histogenesis of the craniofacial skeleton and models of facial growth. In J A McNamara, DS Carlson, and KA Ribbens (eds.): The Effect of Surgical Intervention on Craniofacial Growth. Monograph 12. Ann Arbor: Center for Human Growth and Development, University of Michigan.

Tappen N (1980) The vermiculate surface pattern in the brow ridges of australopithecines and other very ancient hominids. AmJ . Phys. Anthropol . 52:512-528.

Webb SG (1995) Paleopathology of Aboriginal Australians: Health and Disease across a Hunter-Gatherer Continent. Cambridge: Cambridge University Press.

Weidenreich F (1939) Six lectures on Sinanthropus pekinensis and related problems. Bulletin of the Geological Society of China 19:1-110.

Weidenreich F (1943) The Skull of Sinanthropus pekinensis: A Comparative Study of a Primitive Hominid Skull. Palaeontologia Sinica (n.S. D) No. 10 (Whole Series No. 127):1-184.

Woo, J (Wu Rukang) (1965) Preliminary report on a skull of Sinanthropus lantianensis of Lantian, Shensi. Scientia Sinica 14:1032-1036.

Woo, J (Wu Rukang) (1966) The skull of Lantian man. Curr. Anthropol. 7:83-86.

Wu R, and Dong X (1985) Homo erectus in China. In R Wu and J W Olsen (eds.): Palaeoanthropology and Paleolithic Archaeology in the People's Republic of China. New York: Academic Press, pp. 79-89.

Wu X, and Poirier FE (1995) Human Evolution in China: A Metric Description of the F ossils and a Review of the Sites. Oxford: Oxford University Press. 